Markus Hofer · Achim Weber · Karsten Haffner

Ansgar Berlis · Karin Klingel · Marcus Krüger

Reinhard Kandolf · Benedikt Volk

\title{
Acute hemorrhagic leukoencephalitis (Hurst's disease) linked to Epstein-Barr virus infection
}

\begin{abstract}
A 16-year-old girl presented signs of a common cold in combination with a hemolytic crisis. Within 3 days, she developed reduced consciousness and hemiparesis subsequently followed by coma. CT and MRI scans revealed evidence for raised intracranial pressure and an extensive inflammatory process extending from the brain stem up to the thalamus. The patient died within 3 weeks after onset of first symptoms of intracranial pressure despite maximum intensive care. Neuropathological examination revealed disseminated necrotic lesions and perivascular hemorrhages characteristic for acute hemorrhagic leukoencephalitis (Hurst's disease), mainly of the brain stem, diencephalon and cerebellum. Serological results, in situ hybridization and PCR analysis demonstrated an acute Epstein-Barr virus (EBV) infection of the central nervous system. To our knowledge, this is the first reported case of Hurst's disease linked to EBV.
\end{abstract}

\author{
M. Hofer B. Volk \\ Department of Neuropathology, Institute for Pathology, \\ University Hospital Freiburg, Breisacherstr. 64, \\ 79106 Freiburg, Germany \\ E-mail: hofer@nz.ukl.uni-freiburg.de \\ Tel.: +49-761-2705106 \\ Fax: + 49-761-2705050
}

\section{A. Weber $\cdot$ K. Klingel $\cdot$ R. Kandolf}

Department of Molecular Pathology, Institute for Pathology, University Hospital Tübingen, Tübingen, Germany

K. Haffner · M. Krüger

Department for Pediatric and Adolescent Medicine, University Hospital Freiburg, Freiburg, Germany

\footnotetext{
A. Berlis

Department of General Neurosurgery, Neuroradiology Division, University Hospital Freiburg, Freiburg, Germany
}

\section{Introduction}

Acute hemorrhagic leukoencephalitis (AHLE) or Hurst's disease is a severe inflammatory disorder of the central nervous system (CNS) with mostly fatal outcome. Hurst's disease usually evolves following an unspecific respiratory infection in otherwise healthy patients and cause study has been unsuccessful in most reported cases. Progressive neurological deficits dominate the clinical picture, and postmortem investigation of the brain reveals characteristic pathological findings, including perivascular hemorrhages, vessel wall necrosis and extensive necrotic areas often in the cerebrum. Here we report a case of Hurst's disease at an uncommon site of the CNS with major alterations being located predominantly in the brain stem and cerebellum. In addition, we were able to show an acute Epstein-Barr virus (EBV) infection of the CNS by in situ hybridization and polymerase chain reaction (PCR) of cerebrospinal fluid (CSF) and brain tissue samples. This is exceptional since EBV primarily causes infectious mononucleosis, whereas severe neurological complications with fatal outcome are scarce. In particular, Hurst's disease as a complication of an EBV infection has not yet been reported making this case a matter of particular interest.

\section{Case report}

A 16-year-old girl presented to her family doctor with signs of an infection of the upper respiratory tract. Since the age of 6 years, the patient had suffered from several episodes of hemolytic crises of unknown etiology. Otherwise the medical history was unremarkable and vaccinations were done as recommended. Because of an acute hemolytic crisis she was admitted to a local hospital 6 days after her initial presentation. Within 3 days she developed rapidly progressing reduction of consciousness, hemiparesis and anisocoria. Prednisolone was administered, yet within hours she developed respiratory insufficiency. A CT scan of the brain re- 
vealed ischemic lesions of the cerebellum and the brain stem. Therefore, she was transferred to our university's children hospital. On admission she was comatose. Pupils were isocoric, but neither light reaction nor motor reflexes could be triggered, and the EEG showed typical signs of an alpha-waves coma. Laboratory data showed leukocytosis $(47,900 / \mu \mathrm{l})$, elevated $\mathrm{C}$-reactive protein $(12.6 \mathrm{mg} / 100 \mathrm{ml})$ and a hemoglobin concentration of $5 \mathrm{~g} / 100 \mathrm{ml}$. CSF analysis exhibited slightly elevated lactate, protein and cell number. Anti-i-cold agglutinins were detected in the blood at a titer of 1:512. Microorganisms were neither detected in blood, urine nor CSF. MRI images of the head showed signs of an inflammatory process with edema and inhomogeneous contrast enhancement in the cervical cord, brain stem, middle brain, reaching up to the thalamus as well as in the leptomeninges (Fig. 1). The primary diagnosis was encephalitis and a therapy with ceftriaxon, ampicillin and aciclovir, and later dexamethasone, was started and ventricular drainages were applied to lower the intracranial pressure. During the following days her neurological state remained unchanged and leukocyte numbers dropped to normal levels. On day 5 following admission to our hospital the intracranial pressure increased dramatically up to $50-60 \mathrm{mmHg}$. A second CT scan revealed a stenosis of the aqueduct and extensive edematous changes in the middle brain. In the following, the intracranial pressure could no longer be normalized and vasopressor therapy was required to keep the blood pressure within tolerable limits. The following day, two
EEG analyses revealed absence of brain activity. Autopsy was limited to the brain.

\section{Materials and methods}

Neuropathological examination

The brain of the patient was removed within $18 \mathrm{~h}$ after death, and specimens from various brain regions were snap frozen in liquid nitrogen for subsequent DNA analysis. Further specimens were fixed in $2.5 \%$ glutaraldehyde and embedded in Epon-Araldite for electron microscopy. The remaining brain was fixed in $4 \%$ formaldehyde. Specimens for light microscopy were removed and processed as usual. Routine and immunohistochemical stainings including stainings for herpes simplex virus (HSV) type 1, EBV [latent membrane protein 1 (LMP1), M0897, DakoCytomation, Hamburg] and cytomegalovirus (CMV) were performed on 5- $\mu \mathrm{m}-$ thick sections.

\section{In situ hybridization}

Tissue sections of the brain stem ( $5 \mu \mathrm{m}$ thick) were dewaxed and basically hybridized as previously described, with the modification that we used ${ }^{35} \mathrm{~S}$-labeled instead of digoxigenin-labeled EBV-EBER-1 RNA probes [15]. The hybridization procedure and washing steps were
Fig. 1 Magnetic resonance images taken 5 days before the patient's death. A Midline sagittal T2-weigthed MR image demonstrates extensive hyperintensities in the cervical cord, brain stem, cerebellum, mesencephalon, diencephalon, and thalamus. B-D Coronal FLAIR- and post-gadolinium T1-weigthed images reveal the abnormal signal in the brain stem and cerebellum with diffuse contrast enhancement of the parenchyma, primarily involving the leptomeninges. E, F Axial T2-, plain and postcontrast $\mathrm{T} 1$-weighted images show predominantly leptomeningeal enhancement at the upper surface of the cerebellum, vermis, and pontomesencephalon and internal hydrocephalus with ventricular enlargement of the temporal cornua

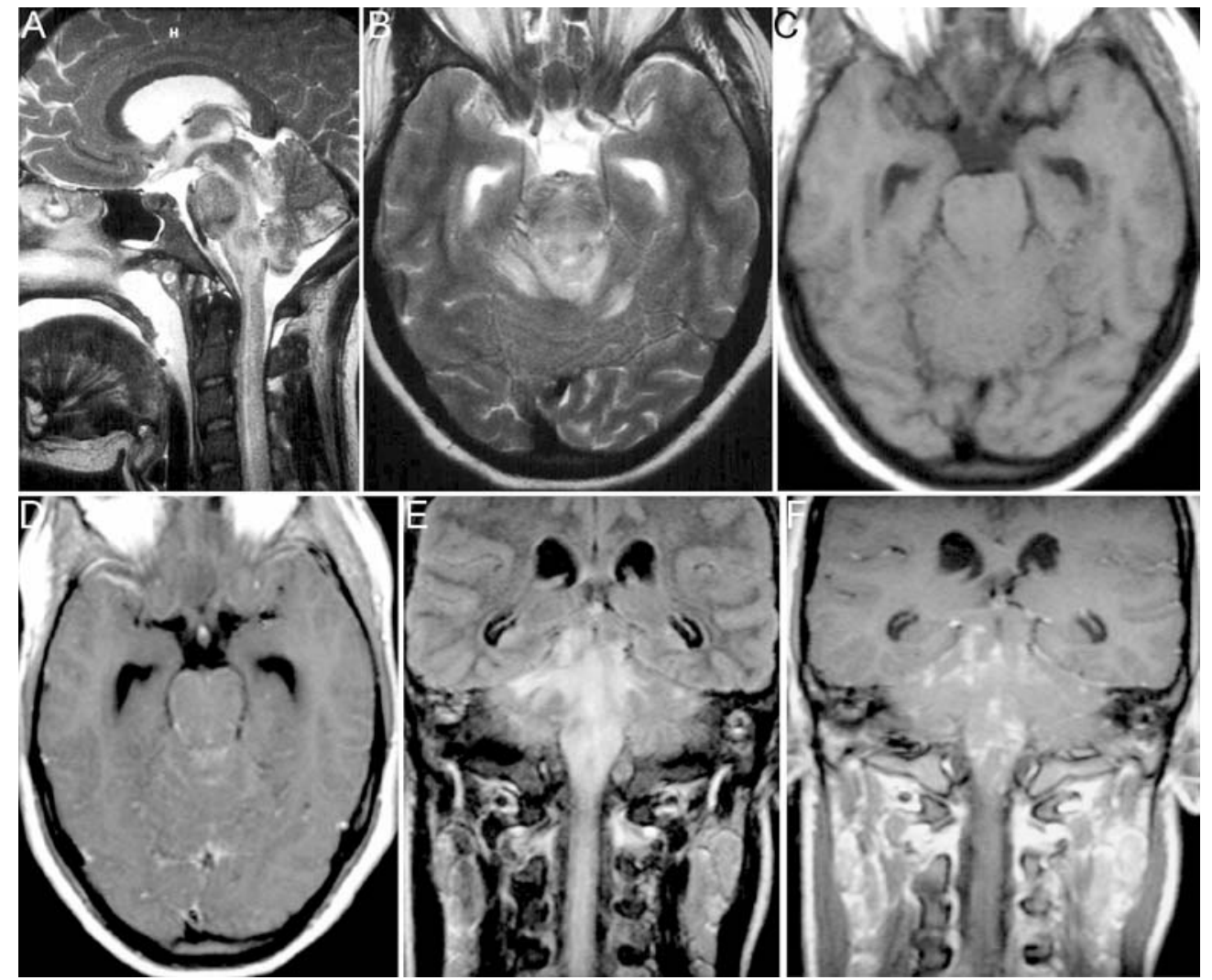


done according to our previous publication [21]. The hybridization mixture contained the ${ }^{35} \mathrm{~S}$-labeled EBV RNA probe $(500 \mathrm{ng} / \mathrm{ml})$ recognizing $550 \mathrm{bp}$ of EBV EBER-1 RNA in $10 \mathrm{mM}$ TRIS-HCl pH 7.4, 50\% (vol/ vol) deionized formamide, $600 \mathrm{mM} \mathrm{NaCl}, 1 \mathrm{mM}$ EDTA, $0.02 \%$ polyvinylpyrrolidone, $0.02 \%$ Ficoll, $0.05 \%$ bovine serum albumin, $10 \%$ dextran sulfate, $10 \mathrm{mM}$ dithiothreitol, $200 \mu \mathrm{g} / \mathrm{ml}$ denatured sonicated salmon sperm DNA and $100 \mu \mathrm{g} / \mathrm{ml}$ rabbit liver tRNA. Hybridization with RNA probes proceeded at $42^{\circ} \mathrm{C}$ for $18 \mathrm{~h}$. Following washing steps, the slide preparations were autoradiographed for 3 weeks and stained with hematoxylin and eosin.

\section{DNA extraction and PCR amplification}

DNA was extracted from frozen tissue samples by a standard protocol [25]. Extracted DNA (200 ng) was used as template DNA for PCR reaction. A nested PCR approach was used, targeting a region of the gene encoding the EBV EBNA-1 protein (GenBank accession number AJ507799; nucleotides 97043-97342). First round amplification was performed using oligonucleotides 5'-AAGGAGGGTGGTTTGGAAAG-3' and 5'AACAGACAATGGACTCCCTTAG- $3^{\prime}$. Of the PCR product from first round amplification, $2 \mu \mathrm{l}$ were used as template for a second round amplification using oligonucleotides 5'-ATCGTGGTCAAGGAGGTTCC-3' and 5'-ACTCAATGGTGTAAGACGAC-3'. PCR reaction mixture included PCR buffer $(50 \mathrm{mmol} / 1 \mathrm{KCl}$, $10 \mathrm{mmol} / 1$ TRIS buffer, pH $8.3,2.5 \mathrm{mmol} / 1 \mathrm{MgCl}_{2}$ ), $200 \mu \mathrm{mol} / 1$ of each dNTP, $1 \mu \mathrm{M}$ of each oligonucleotide, and $0.3 \mathrm{U}$ Taq polymerase (Perkin Elmer, Foster City, $\mathrm{CA}$ ) in a final volume of $50 \mu \mathrm{l}$. Amplification was performed in a GeneAmp PCR System 9700 (Foster City, CA) using the following conditions: initial denaturation at $94^{\circ} \mathrm{C}$ for $5 \mathrm{~min}$, followed by 35 cycles of denaturation at $95^{\circ} \mathrm{C}$ for $30 \mathrm{~s}$, annealing at $56^{\circ} \mathrm{C}$ for $30 \mathrm{~s}$, and extension at $72^{\circ} \mathrm{C}$ for $45 \mathrm{~s}$. PCR products were analyzed on a $2 \%$ standard agarose gel after ethidium bromide staining.

\section{Results}

Macroscopically, the brain showed extensive necrotic areas and numerous punctual hemorrhages (purpura cerebri, Fig. 2A, B) mainly in the cerebellar hemispheres, diencephalon and the brain stem, comprising up to $30 \%$ of the cross-section. The most prominent histological features were necrotic vessels with fibrinoid changes and numerous perivascular ring or ball hemorrhages (Fig. 2C). Immunohistochemistry revealed cuffs of mononuclear cells around smaller vessels. The parenchyma showed a diffuse infiltration by macrophages and lymphocytes, as well as activated microglial cells and reactive astrocytosis (Fig. 2D, E). The remaining brain areas revealed only minor or no overt pathological alterations. In addition, extensive infiltrations with LCA- and CD68-positive cells were seen in the meninges. Immunohistochemistry against HSV1, CMV and EBV (LMP1) in sections of various brain regions showed negative or unspecific results. It is worthy to note that in contrast to latent infection, LMP1 is rarely expressed during acute disease [13], explaining the negative immunohistochemical result. However, serological results received after the patient's death showed positive titers for EBV-VCA IgG $(1: 8,000)$, IgM (1:60), and EBV-EA IgG (1:512), indicating an acute EBV infection. In addition, EBV-infection of the brain was demonstrated by the detection of EBER-1 RNA in single immune cells within or around small vessels (Fig. 2F). Furthermore, PCR analyses from CSF sampled 4 days before the patient's death and from frozen tissue of four different brain regions (parietal lobe, cerebellum, pons, medulla oblongata) were clearly positive for EBV-DNA (Fig. 3). Electron microscopy performed on material from the brain stem and cerebellum revealed no viral particles, but necrosis reduced the significance noticeably.

\section{Discussion}

Acute leukoencephalitides are rare but severe complications of peripheral virus infections or vaccinations. Among them AHLE or Hurst's disease is the most severe form [1, 18]. It typically develops following an infection of the respiratory tract and begins with abrupt onset of fever, neck stiffness, hemiplegia and other focal signs $[5,11,12,14,19]$. Respiratory paralysis following upper and lower herniation of the brain due to increased intracranial pressure occurs within few days and causes death in the majority of cases. Cerebral edema with tissue necrosis are particularly pronounced in the centrum semiovale, internal capsule and convolutional white matter of the cingulate gyrus, and may extend down into the midbrain, pons and cerebellar peduncles causing tonsillar herniation. Histologically, petechial hemorrhages surrounding smaller vessels in combination with vasculitis and fibrinoid vessel wall necrosis are the most prominent features.

In contrast to this, acute disseminated leukoencephalitis (ADEM) or postinfectious perivenous encephalomyelitis (PVE) represents the milder variant $[8,24]$. The clinical course is likewise dominated by neurological deficits [9, 14], but symptoms are mostly less severe and the outcome is significantly more favorable [7, 23, 28]. Histopathological findings include lymphocytic infiltration, perivascular demyelination and necrosis, whereas perivascular hemorrhages and necrosis of blood vessels are absent [14].

Up to now, the pathogenesis of both Hurst's disease and ADEM/PVE has remained unclear, but may involve several causative agents. In Hurst's disease, the presence of viruses (HSV, VZV, HHV6, measles, mumps) [3, 14] could be demonstrated only in few patients, while in 

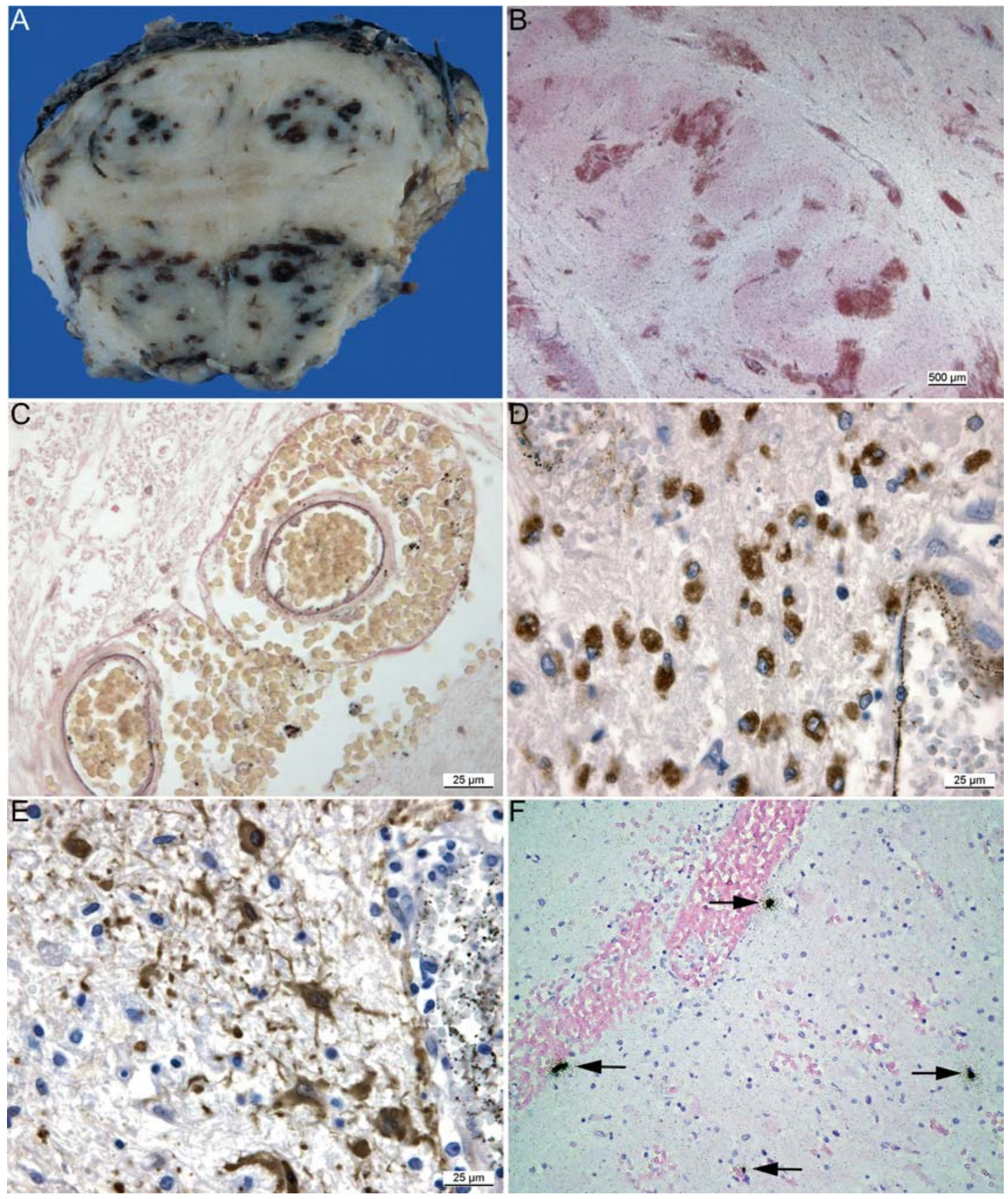

Fig. 2 Macroscopy and histology from the necropsy. A shows a macroscopic picture of the middle brain with various hemorrhages and necrobiotic changes. B Hematoxylin and eosin stain of the brain stem depicts numerous hemorrhages. They are located frequently around necrotic vessels. C Elastica-van-Giesson staining. In addition, immunohistochemistry reveals numerous macrophages $(\mathbf{D}, \mathbf{C D} 68)$ and a pronounced reactive astrocytosis $(\mathbf{E}$, glial fibrillary acidic protein). In situ hybridization (F) for EBER-1 RNA shows single EBV-positive cells within and around small vessels (arrows). Original magnification $\mathbf{B} \times 10 ; \mathbf{C}-\mathbf{E} \times 40$

most cases, including two cases in our department, it has been impossible to identify a cause.

Here, we demonstrate a case of Hurst's disease that can be linked to an acute EBV infection, as shown by distinctly elevated titers for EBV VCA IgM, and detection of EBV DNA in CSF and brain tissue by PCR and

of EBV EBER-1 RNA in infiltrating immune cells by in situ hybridization. Mild neurological symptoms are a common finding in patients with an acute EBV infection, and severe neurological complications occur in less than $0.5 \%[6,27]$ with complete recovery of most patients [20]. While few patients displayed pathological changes compatible with the diagnosis of ADEM/PVE [2, 4, 10, 17], to our knowledge, EBV has not yet been demonstrated as being concurrently causative for Hurst's disease. Although our results do not prove virus replication within the CNS, the co-ocurrence of acute EBV infection and Hurst's disease strongly indicates a causative link. Interestingly, in our patient anti-i-agglutinins were detected, which is an occasional finding in patients with a hemolytic crisis during an EBV infection [16, 22, 26]. 


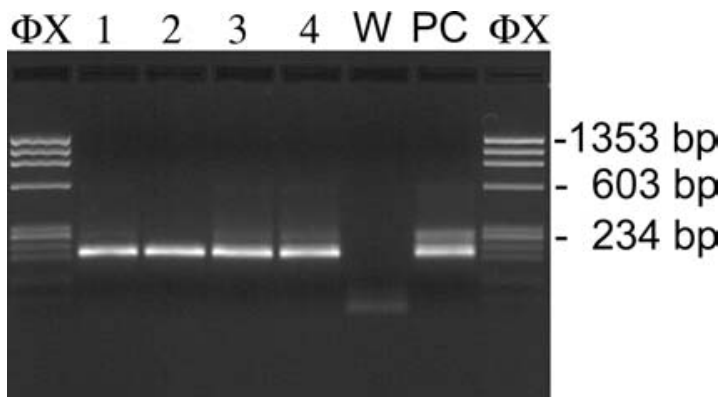

Fig. 3 Detection of EBV genome in brain tissue by nested-PCR. The presence of EBV-specific DNA sequences in autopsy tissues from different areas of the central nervous system was confirmed by nested-PCR ( $\Phi \mathrm{X} \Phi \mathrm{X} / \mathrm{HaeIII}$ digest, 1 parietal lobe, 2 cerebellum, 3 pons, 4 medulla oblongata, $W$ water control, $P C$ positive control)

However, no tight association between hematological complications and encephalitis has been established so far. It is conceivable that impaired cellular and humoral immunity, as a consequence of hemolysis, may have favored virus-associated encephalitis in this case.

Because PCR analysis and in situ hybridization are not routinely applied for EBV diagnostics in most laboratories EBV infection may have been overlooked in reported cases of Hurst's disease of unknown cause. Further studies based on sensitive PCR and in situ hybridization techniques will have to clarify the frequency of EBV involvement in the development of Hurst's disease.

Acknowledgement We thank Viviana Sverdlick and Christine el Gaz for their excellent technical assistance.

\section{References}

1. Adams RD, Cammermeyer J, Denny-Brown D (1949) Acute necrotizing hemorrhagic encephalopathy. J Neuropathol Exp Neurol 8:1-49

2. Ambler M, Stoll J, Tzamaloukas A, Albala MM (1971) Focal encephalomyelitis in infectious mononucleosis. A report with pathological description. Ann Intern Med 75:579-583

3. An SF, Groves M, Martinian L, Kuo LT, Scaravilli F (2002) Detection of infectious agents in brain of patients with acute hemorrhagic leukoencephalitis. J Neurovirol 8:439-446

4. Bray PF, Culp KW, McFarlin DE, Panitch HS, Torkelson RD, Schlight JP (1992) Demyelinating disease after neurologically complicated primary Epstein-Barr virus infection. Neurology 42:278-282

5. Byers RK (1975) Acute hemorrhagic leukoencephalitis: report of three cases and review of the literature. Pediatrics 56:727-735

6. Corssmit EP, Leverstein-van Hall MA, Portegies P, Bakker P (1997) Severe neurological complications in association with Epstein-Barr virus infection. J Neurovirol 3:460-464

7. Fenichel GM (1982) Neurological complications of immunization. Ann Neurol 12:119-128

8. Ferraro A, Roizin L (1954) Neuropathologic variations in experimental allergic encephalomyelitis, hemorrhagic encephalomyelitis, perivenous encephalomyelitis, diffuse encephalomyelitis, patchy gliosis. J Neuropathol Exp Neurol 13:60-89
9. Fisher RS, Clark AW, Wolinsky JS, Parhad IM, Moses H, Mardiney MR (1983) Postinfectious leukoencephalitis complicating Mycoplasma pneumoniae infection. Arch Neurol 40:109113

10. Fujimoto H, Asaoka K, Imaizumi T, Ayabe M, Shoji H, Kaji M (2003) Epstein-Barr virus infections of the central nervous system. Intern Med 42:33-40

11. Geerts Y, Dehaene I, Lammens M (1991) Acute hemorrhagic leukoencephalitis. Acta Neurol Belg 91:201-211

12. Graham DI, Lantos PL (1997) Viral diseases. In: Graham DI, Lantos PL (eds) Greenfield's neuropathology, 6th edn. Arnold, London, pp 3-64

13. Gulley ML (2001) Molecular diagnosis of Epstein-Barr virusrelated diseases. J Mol Diagn 3:1-10

14. Hart MN, Earle KM (1975) Haemorrhagic and perivenous encephalitis: a clinical-pathological review of 38 cases. J Neurol Neurosurg Psychiatry 38:585-591

15. Herrlinger U, Klingel K, Meyermann R, Kandolf R, Kaiserling E, Kortmann RD, Melms A, Skalej M, Dichgans J, Weller M (2000) Central nervous system Hodgkin's lymphoma without systemic manifestation: case report and review of the literature. Acta Neuropathol 99:709-714

16. Horwitz CA, Moulds J, Henle W, Henle G, Polesky H, Balfour HH Jr, Schwartz B, Hoff T (1977) Cold agglutinins in infectious mononucleosis and heterophil-antibody-negative mononucleosis-like syndromes. Blood 50:195-202

17. Hung KL, Liao HT, Tsai ML (2000) Postinfectious encephalomyelitis: etiologic and diagnostic trends. J Child Neurol 15:666-670

18. Hurst WE (1941) Acute haemorrhagic leucoencephalitis: a previously undefined entity. Med J Aust 11:1-6

19. Kaluza J, Krygowska-Wajs A, Czapinski P (1998) Acute hemorrhagic encephalitis (Hurst disease) associated with neuroaxonal dystrophy. Folia Neuropathol 36:221-224

20. Kleinschmidt-DeMasters BK, Gilden DH (2001) The expanding spectrum of herpesvirus infections of the nervous system. Brain Pathol 11:440-451

21. Klingel K, Hohenadl C, Canu A, Albrecht M, Seemann M, Mall G, Kandolf R (1992) Ongoing enterovirus-induced myocarditis is associated with persistent heart muscle infection: quantitative analysis of virus replication, tissue damage, and inflammation. Proc Natl Acad Sci USA 89:314-318

22. Konig AL, Schabel A, Sugg U, Brand U, Roelcke D (2001) Autoimmune hemolytic anemia caused by IgG lambda-monotypic cold agglutinins of anti-Pr specificity after rubella infection. Transfusion 41:488-492

23. Poser CM (1969) Disseminad vasculomyelinopathy. A review of the clinical and pathologic reactions of the nervous system in hyperergic diseases. Acta Neurol Scand Suppl 37:3-44

24. Russell DS (1955) The nosological unity of acute haemorrhagic leucoencephalitis and acute disseminated encephalomyelitis. Brain 78:369-376

25. Sambrook J, Fritsch EF, Maniatis T (1989) Molecular cloning: a laboratory manual. Cold Spring Harbor Press, Cold Spring Harbor

26. Terness P, Kirschfink M, Navolan D, Dufter C, Kohl I, Opelz G, Roelcke D (1995) Striking inverse correlation between IgG anti-F(ab')2 and autoantibody production in patients with cold agglutination. Blood 85:548-551

27. Todman DH (1983) Encephalitis in infectious mononucleosis Clin Exp Neurol 19:81-86

28. Tselis AC, Lisak RP (1995) Acute disseminated encephalomyelitis and isolated central nervous system demyelinative syndromes. Curr Opin Neurol 8:227-229 